\title{
14th St. Gallen International Breast Cancer Conference 2015: Evidence, Controversies, Consensus - Primary Therapy of Early Breast Cancer: Opinions Expressed by German Experts
}

Christian Jackisch $^{a}$ Nadia Harbeck ${ }^{b}$ Jens Huober ${ }^{c}$ Gunter von Minckwitz ${ }^{d}$ Bernd Gerber Hans-Heinrich Kreipe $^{f}$ Cornelia Liedtke $^{g} \quad$ Norbert Marschner $^{\text {h }} \quad$ Volker Möbus $^{i}$ Heike Scheithauer ${ }^{j}$ Andreas Schneeweiss ${ }^{k}$ Christoph Thomssen' Sibylle Loibl ${ }^{m}$ Matthias W. Beckmann ${ }^{n}$ Jens-Uwe Blohmer ${ }^{\circ}$ Serban-Dan Costa $^{p}$ Thomas Decker ${ }^{q}$ Ingo Diel ${ }^{r}$ Peter A. Fasching ${ }^{s}$ Tanja Fehm ${ }^{t}$ Wolfgang Janni ${ }^{u}$ Hans-Joachim Lück ${ }^{v}$ Nicolai Maassw Anton Scharl ${ }^{x}$ Michael Untch ${ }^{\mathrm{y}}$

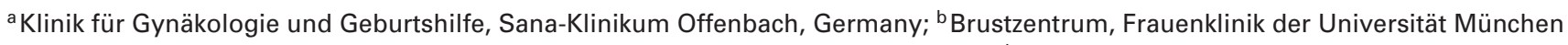
(LMU), München, Germany; ${ }^{\mathrm{C} B r u s t z e n t r u m, ~ U n i v e r s i t a ̈ t s f r a u e n k l i n i k ~ U l m, ~ G e r m a n y ; ~}{ }^{\mathrm{d}}$ German Breast Group, Neu-Isenburg, UniversitätsKlinikum Frankfurt and Senologische Onkologie, Düsseldorf, Germany; ${ }^{e}$ Universitätsfrauenklinik Rostock, Germany; ${ }^{\mathrm{f}}$ Institut für Pathologie, Medizinische Hochschule Hannover, Germany; ${ }^{9}$ Klinik für Frauenheilkunde und Geburtshilfe, Universitätsklinikum Schleswig-Holstein,

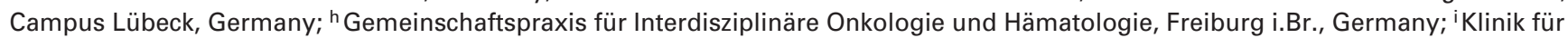
Gynäkologie und Geburtshilfe, Klinikum Frankfurt-Höchst, Frankfurt/M., Germany; ${ }^{j}$ Klinik und Poliklinik für Strahlentherapie und Radioonkologie, LMU München, Germany; ${ }^{k}$ Nationales Centrum für Tumorerkrankungen (NCT) und Universitätsfrauen-klinik Heidelberg, Germany; 'Universitätsklinik und Poliklinik für Gynäkologie, Halle (Saale), Germany; ${ }^{m}$ German Breast Group, Neu-Isenburg; Klinik für Gynäkologie und Geburtshilfe, Sana-Klinikum Offenbach, Germany; ${ }^{n}$ Frauenklinik des Universitätsklinikums Erlangen, Comprehensive Cancer Center Erlangen, Germany; ${ }^{\circ}$ Klinik für Gynäkologie und Brustzentrum, Charité Berlin-Mitte, Berlin, Germany;

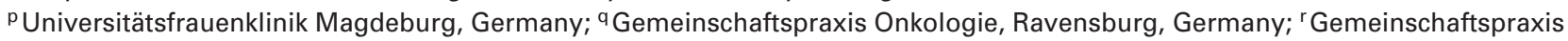

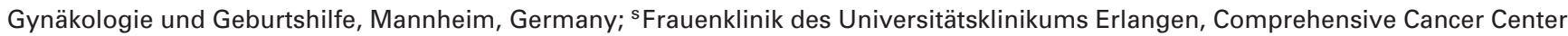

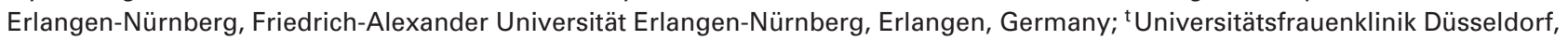
Germany; " Universitätsfrauenklinik Ulm, Germany; ${ }^{\vee}$ Gynäkologisch-Onkologische Praxis, Hannover, Germany; ${ }^{\text {w} K l i n i k ~ f u ̈ r ~ G y n a ̈ k o l o g i e ~}$ und Geburtshilfe, Universitätsklinikum Schleswig-Holstein, Campus Kiel, Germany; ${ }^{\times}$Frauenklinik, Klinikum St. Marien, Amberg,



\section{Keywords}

St. Gallen Consensus 2015 - Systemic therapy ·

Local therapy - Sentinel node biopsy - Endocrine therapy . Targeted substances · Multigene assay

\section{Summary}

The key topics of this year's 14th St. Gallen Consensus Conference on the diagnosis and therapy of primary breast cancer were again questions about breast sur-

$\mathrm{NH}, \mathrm{JH}$, and GvM are St. Gallen Panel Experts.

The vote of the German group of experts has been published in part in Geburtsh Frauenheilk 2015;75: DOI 10.1055/s-0035-1546120. gery and axillary surgery, radio-oncology and systemic therapy options in consideration of tumor biology, and the clinical application of multigene assays. This year, the consensus conference took place in $\mathrm{Vi}$ enna. From a German perspective, it makes sense to substantiate the results of the vote of the international panel representing 19 countries in light of the updated national therapy recommendations of the AGO (Arbeitsgemeinschaft Gynäkologische Onkologie). Therefore, 14 German breast cancer experts, 3 of whom are members of the International St. Gallen Panel, have commented on the voting results of the St. Gallen Consensus Conference 2015 in relation to clinical routine in Germany.

\section{KARGER \\ Fax +497614520714

\section{() 2015 S. Karger GmbH, Freiburg}

$1661-3791 / 15 / 0103-0211 \$ 39.50 / 0$
Prof. Dr. med. Christian Jackisch 


\section{Introduction}

The panel of this year's 14th St. Gallen International Breast Cancer Conference comprised 49 experts from 19 countries, 3 of whom were from Germany. Recommendations are based on the majority vote of the panelists who represented various disciplines and countries with different healthcare systems and resources. Therefore, these are rather personal opinions which are in part based on evidence [1]. In light of these facts, however, it makes sense to discuss the voting results critically with regard to the national therapy recommendations of the AGO (Arbeitsgemeinschaft Gynäkologische Onkologie) guideline commission from 2015 [2].

\section{Rationale and Voting Rules of the St. Gallen Consensus}

The St. Gallen Consensus aims essentially at panel members forming a majority and giving a practical opinion. Some questions were answered with 'yes' (consent), 'no' (rejection), or 'abstention' (insufficient data; inability to form an opinion) while others required choosing from several options.

\section{Surgical Therapy}

\section{Resection Margin after Breast-Conserving Surgery}

With regard to breast-conserving therapy, the panelists demand unanimously resection with tumor-free resection margins (R0) (no invasive tumor cells on ink).

Vote of the German group of experts: Consent.

According to the majority vote in St. Gallen, breast-conserving surgery (BCS) can be performed both in multifocal (yes: 71\%) as well as multicentric (unilateral; yes: $80 \%$ ) invasive breast cancer, provided the resection margin is tumor-free and patients receive adjuvant radiation therapy.

Comment of the German group of experts: Limited consent. According to the 2015 AGO recommendation, BCS must be based on an individual decision in multicentric (unilateral) breast cancer [2]. Another option is modified mastectomy with immediate reconstruction.

The size of the resection margin should not depend on tumor biology. An additional (larger) margin is not necessary in younger patients ( $<40$ years) and patients with lobular breast cancer. The same applies to surgery following neoadjuvant chemotherapy (NACT) or if there is an extensive intraductal component.

Vote of the German group of experts: Consent. However, for ductal carcinoma in situ, the German group recommends a resection margin of at least $2 \mathrm{~mm}$ after BCS [2].

\section{Surgical Approach Following NACT}

The question of whether it is sufficient to perform a sentinel node biopsy (SNB) or whether a complete axillary lymph node dissection (ALND) should be performed in a patient who has palpatory and/or sonographically suspicious lymph nodes $(\mathrm{cN}+)$ at presentation but clinically/sonographically uninvolved axillary nodes (ycN0) following NACT (so-called 'down-staging'), was extensively discussed. The majority of the St. Gallen panelists believe
Surgical Procedure of the Axilla Before or After NACT

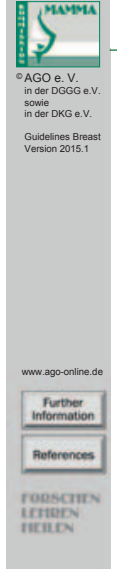

\begin{tabular}{|c|c|c|c|c|c|c|}
\hline & & & & $\begin{array}{l}\text { Oxfo } \\
\text { LoE I }\end{array}$ & $\begin{array}{l}d / A \\
G R\end{array}$ & \\
\hline SLNB before 0 & fter NACT in $\mathrm{CNO}$ & & & & & \\
\hline $\begin{array}{l}\text { SLNB before N } \\
\text { SLNB after NA }\end{array}$ & & & & $\begin{array}{l}2 \mathrm{~b} \\
2 \mathrm{a}\end{array}$ & $\begin{array}{l}\text { B } \\
B\end{array}$ & $\begin{array}{l}+ \\
+1-\end{array}$ \\
\hline Further surgice & procedures deper & ing on SLNB & & & & \\
\hline $\begin{array}{c}\mathrm{cN}-\mathrm{Status} \\
\text { (before NST) }\end{array}$ & $\begin{array}{c}\text { pN-Status } \\
\text { (before NST) }\end{array}$ & $\begin{array}{l}\text { cN-Status } \\
\text { (after NST) }\end{array}$ & $\begin{array}{c}\text { Surgical } \\
\text { procedure }\end{array}$ & & & \\
\hline cNO & pNO(sn) & - & nihil & 1a & A & + \\
\hline cNO & $\begin{array}{l}\mathrm{pN}+(\mathrm{sn}) \\
\text { analogue } \\
\text { ACOZOG }\end{array}$ & ycNO & ALND & 3 & B & $+1-$ \\
\hline cNO & $\begin{array}{l}\text { pN+(sn) not } \\
\text { analogue } \\
\text { ACOZOG }\end{array}$ & ycNO & ALND & $2 \mathrm{~b}$ & B & + \\
\hline $\mathrm{cN}+$ & $\mathrm{cN}+(\mathrm{CNB} / \mathrm{FNA})$ & ycNo & $\begin{array}{l}\text { SNB } \\
\text { ALND }\end{array}$ & $\begin{array}{l}2 \mathrm{a} \\
2 \mathrm{~b}\end{array}$ & $\begin{array}{l}B \\
B\end{array}$ & + \\
\hline & & $y c N+(C N B / F N A)$ & ALND & $2 \mathrm{~b}$ & B & ++ \\
\hline
\end{tabular}

Fig. 1. Surgical procedure of the axilla before or after NACT.

SLNB = Sentinel lymph node biopsy; NACT = neoadjuvant chemotherapy LoE = level of evidence; $\mathrm{GR}$ = grade of recommendation; $\mathrm{BET}=$ breast-conserving therapy; ALND = axillary lymphadenectomy; $\mathrm{CNB}=$ core needle biopsy; FNA = fine needle aspiration; ACOSOG = American College of Surgeons Oncology Group.

that SNB is an adequate approach in patients following NACT. However, the St. Gallen panel believes that ALND should be performed if 1 or more sentinel lymph nodes are infiltrated.

Vote of the German group of experts: Consent. This recommendation is based on data of the ACOSOG study Z1071 [3]. The German group adds that fine needle aspiration (FNA) or punch biopsy prior to NACT should be performed in clinically suspicious lymph nodes. If possible, the lymph node in question should be marked with a clip. In the case of ycN0, the German group recommends deciding on an individual basis whether SNB or ALND should be performed [2]. If patients with $\mathrm{cN}+$ (proven by FNA or biopsy) prior to NACT undergo an SNB procedure after NACT, the decision for ALND depends on the number of removed (sentinel and non-sentinel) lymph nodes.

Moreover, the German group points out that only with 3 tumor-free lymph nodes the false-negative rate (FNR: negative sentinel node but positive axillary) is similar to the FNR with a primary surgical approach. In these cases, the possibility to avoid ALND should be discussed with the patient. However, ALND should be performed in a patient with histologically positive lymph node(s) (by FNA or biopsy) prior to NACT and 1-2 positive sentinel (and non-sentinel) lymph nodes following NACT (ypN+ SN) [3-5] (fig. 1). Breast surgery following NACT should be performed within the new margins.

According to the St. Gallen vote, ALND is not required if 1-2 macrometastatically infiltrated sentinel lymph nodes are detected at primary surgery, provided that ACOSOG Z0011 criteria [6] are fulfilled (tumor $\leq 5 \mathrm{~cm}$ (pT1-2), no extracapsular lymph node involvement, BCS, adequate adjuvant systemic therapy, adjuvant postoperative tangential field radiation).

Vote of the German group of experts: Consent. After mastectomy, ALND should be performed in the case of macrometastati- 
cally involved sentinel lymph nodes [2]. If patients receive postoperative adjuvant radiotherapy to the chest wall, the alternative to ALND is radiotherapy in the axillary field.

\section{Adjuvant Radiation Therapy}

\section{Partial Breast Radiation after BCS}

The majority of the St. Gallen panelists believe that partial irradiation without whole breast radiation is possible for patients who are classified as 'suitable' according to the ASTRO (American Society for Radiation Oncology) and ESTRO (European Society for Radiotherapy and Oncology) criteria [7, 8].

Comment of the German expert group: ASTRO classifies patients as 'suitable' if they meet the following criteria: $\geq 60$ years, no BRCA1/2 mutation, hormone receptor (HR)-positive, tumor $\leq 2 \mathrm{~cm}$ (T1), clear margin $\geq 2 \mathrm{~mm}$, pN0, no lymph vessel infiltration (L0), unicentric/unifocal, invasive ductal or other favorable histology (mucinous, tubular, colloid), missing extensive intraductal component. In patients with DCIS or preceding neoadjuvant chemotherapy, partial breast irradiation is not indicated. However, first positive data have been published on intraoperative radiotherapy (IORT) following NACT. The selection criteria ('suitable') of ESTRO and ASTRO differ only slightly with regard to age ( $\geq 50$ vs. $\geq 60$ years) and T-stage (pT1-2 vs. T1). Other than that, the ASTRO criteria fully apply [7-10].

The St. Gallen panel recommends for patients classified as 'intermediate' by ESTRO and as 'cautionary' by ASTRO $[7,8]$ to await the results from studies with partial breast irradiation.

Comment of the German expert group: The patient selection criteria are not sufficiently defined. In this context, it is recommended to conduct further clinical trials. In addition, the German expert group refers to the current AGO recommendations 2015 [2]. Currently, there is no general standard for partial breast radiation therapy alone. Partial breast irradiation should be discussed on an individual basis with patients who have favorable tumor biology and a low risk of recurrence (see [2]).

\section{Hypofractionated Radiation Following BCS}

The St. Gallen panelists believe that hypofractionated radiation is indicated regardless of age. In addition, according to the St. Gallen vote, it is also indicated for patients with prior chemotherapy or axillary lymph node involvement regardless of age; therefore, irradiation of the lymphatic drainage areas would also be indicated.

Vote of the German group of experts: No consent. The German experts recommend a significantly more differentiated approach as specified in the current AGO recommendations (fig. 2) [2]. The German experts believe that hypofractionated radiation (without boost; 15-16 fractions with 2.67 Gy each) following BCS is preferable for patients $>65$ years with low risk factors (see ASTRO and ESTRO criteria) over normofractionation (25 fractions of 2 Gy each). In 40-65-year-old patients with higher risk factors, both conventional radiation with integrated or sequential boost and hy-

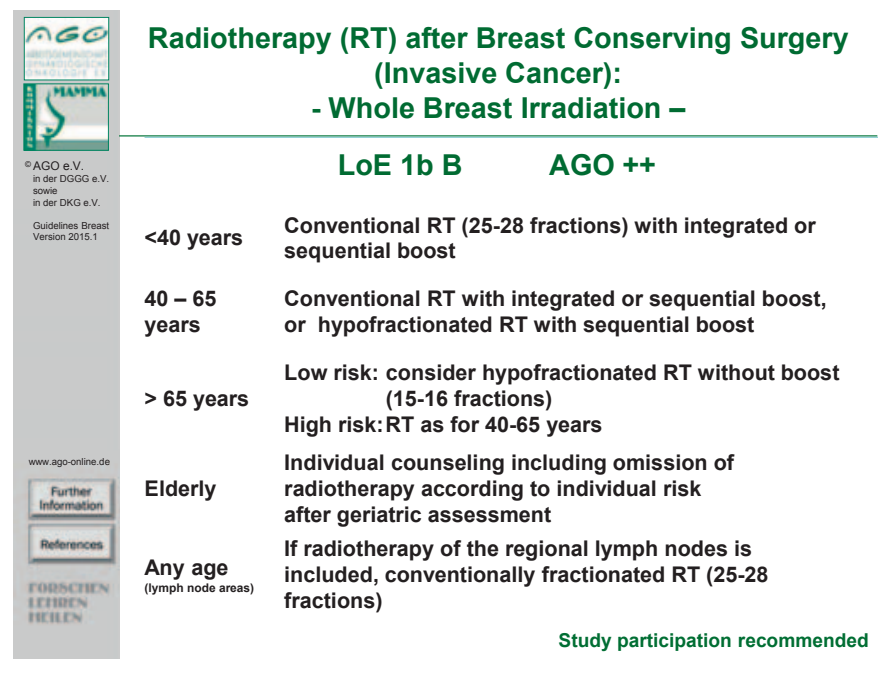

Fig. 2. Radiotherapy (RT) after breast-conserving surgery (invasive cancer): whole breast irradiation (LoE: Level of evidence).

pofractionated radiation with sequential boost are valid treatment options. The AGO does not believe that hypofractionated radiation is indicated in women younger than 40 years nor if irradiation of the supra-infraclavicular lymphatic drainage areas is indicated; in these cases, conventional radiation is recommended.

Radiotherapy to the Lymphatic Drainage Areas Following BCS

Patients without lymph node involvement (pN0) do not require adjuvant radiation therapy of the lymphatic drainage areas following BCS. Sole radiation therapy to the breast is insufficient in patients with lymph node involvement. These patients receive radiation therapy to the regional lymph nodes, however, not including the internal mammary lymph nodes.

Vote of the German group of experts: Consent. In addition, the German group of experts refers to the current AGO guideline 2015 [2], differentiating between $1-3$ and $\geq 4$ involved lymph nodes. According to AGO, if 4 or more lymph nodes are involved, there is an indication for additional radiotherapy to the lymphatic drainage areas. If 1-3 lymph nodes are involved, DEGRO (German Society for Radiation Oncology) and AGO differ in their interpretation of the data. DEGRO considers this intervention as indicated if 1-3 lymph nodes are involved while according to AGO it is indicated only if additional risk factors such as young age and unfavorable tumor biology are present.

\section{Radiotherapy Following Mastectomy}

In this case, a differentiation must be made between the indication for radiation therapy to the thoracic wall and radiation therapy to the lymphatic drainage areas. Radiation therapy to the lymphatic drainage areas follows the same rules as that after BCS. AGO recommends [2] for patients after mastectomy adjuvant radiation therapy to the thoracic wall as standard in T3/T4 carcinomas (except 'low risk'), in involved lymph nodes (DEGRO recommends it at 'any risk', AGO differentiates here between 'high' and 'low risk'), as well as for patients in whom R0 resection could not be achieved. 
The majority of the St. Gallen panelists confirm that patients should receive adjuvant radiation therapy after mastectomy and with a tumor size of more than $5 \mathrm{~cm}$. They do not believe that adjuvant radiation therapy is generally indicated in patients with 1-3 involved lymph nodes; however, they recommend it if the tumor biology is unfavorable. Moreover, half of the panelists believe that adjuvant radiation therapy is indicated in young women $(<40$ years) with 1-3 involved lymph nodes.

Vote of the German group of experts: Consent. In accordance with the AGO recommendation 2015 [2], the indication should be risk-adapted, specifically in patients with 1-3 involved axillary lymph nodes. According to AGO, a low local risk of recurrence can be assumed if at least the following 4 factors are present: pT1, grade 1, HR-positive, HER2-negative. At a younger age ( $<45$ years), an increased local risk of recurrence is assumed if the tumor location is medial or the HR status is negative [2].

The St. Gallen panelists believe that adjuvant radiation therapy is indicated after mastectomy and in patients with positive SNB if an ALND was not performed. The panelists believe it is not indicated if the lymph nodes were tumor-free ( $\mathrm{pN}$ ) following ALND, if no SNB was performed, and if less than 8 lymph nodes were removed and histologically examined.

Comment of the German group of experts: The German group refers again to the AGO recommendations 2015 [2], recommending an indication for adjuvant radiation therapy after mastectomy in pT3 pN0 patients dependent on the risk constellation: Without additional risk factors, adjuvant radiation therapy is a 'can' option; in young women with increased risk (e.g. an unfavorable tumor biology), adjuvant radiation is strongly recommended (LoE 1a A ++).

If adjuvant radiotherapy is indicated after mastectomy, the majority of the St. Gallen panelists voted for applying radiation therapy to the regional lymph nodes - without including the internal mammary lymph nodes - in addition to the thoracic wall. However, one third of the panelists abstained from voting.

Comment of the German group of experts: According to the AGO recommendation - in accordance with the data of the EORTC study by Poortmans et al. [11] - adjuvant radiation therapy to the internal mammary lymphatic drainage region can be considered in stage $\mathrm{pN} 1-2$ with positive HR expression if adjuvant chemotherapy was administered due to an overall high risk (LoE $2 \mathrm{~b}++)$. In pN0 patients with centrally or medially located breast cancer and increased risk, there is no strong recommendation for thoracic wall radiotherapy; this should be individually discussed with the patient (AGO recommendation 2015: LoE 1b B +/-). Adjuvant radiation therapy to the internal mammary lymph node region should not be performed in the case of cardiac risk or trastuzumab therapy [2].

In the case of breast reconstruction, the St. Gallen panel recommends radiation of the thoracic wall and the regional lymphatic drainage area without the internal mammary lymph nodes.

Comment of the German group of experts: The indication for adjuvant radiation therapy should be clarified prior to reconstruction (increased rate of capsular fibrosis, worse cosmetic results, higher complication rate in late reconstructions). This must be carefully considered and discussed with the patient, particularly in the case of node-negative breast cancer or 1-3 involved lymph nodes.

After NACT, the indication for adjuvant radiation therapy is based on the initial tumor stage (before NACT), especially in consideration of lymph node involvement histologically verified by FNA or biopsy or a positive sentinel lymph node.

Vote of the German group of experts: Consent.

\section{Focus on Pathology}

In general, the subtypes luminal A or luminal B (HER2-negative) can be differentiated from one another by the estrogen receptor (ER) and progesterone receptor (PR) status and the proliferation marker $\mathrm{Ki}-67$. If Ki-67 is considered as a decision-making criterion, then one part of the St. Gallen panelists (36.4\%) require a Ki-67 level of at least $20-29 \%$ as cut-off for a luminal B carcinoma. Uncertainty with regard to the subtype assignment and the therapeutic consequences is still present in intermediate Ki-67 levels of $10-13 \%$.

Comment of the German group of experts: In luminal A breast cancers, the Ki-67 level is likely to be $\leq 10 \%$, even if it is not possible to define a clear cut-off level.

According to the St. Gallen vote, risk stratification with multigene expression tests cannot replace immunohistological determination of the intrinsic subtype but can supplement it in doubtful cases. For differentiation between luminal A and luminal B type (HER2negative) breast cancer, a multigene expression test is only helpful in unclear cases, e.g. with an intermediary Ki-67 level of 10-35\%.

Vote of the German group of experts: Consent.

In triple-negative breast cancer (TNBC) or HER2-positive breast cancer, the role of tumor-infiltrating lymphocytes was discussed. According to the majority votes of the St. Gallen panelists, the extent of lymphocyte infiltration is currently neither a prognostic nor a predictive marker.

Vote of the German group of experts: Consent. It is anticipated that new research results show that lymphocytes will have predictive and potentially therapy-relevant significance in the future [12].

\section{Significance of Multigene Expression Signatures}

The St. Gallen panel voted individually on the prognostic and predictive value of each of the multigene assays currently available: Oncotype DX ${ }^{\circledR}$ Recurrence Score (RS) (Genomic Health, Inc., Redwood City, CA, USA), MammaPrint $70^{\circledR}$ (MP) (Agendia Inc., Irvine, CA, USA), Prosigna ${ }^{\circledR}$ PAM50 Risk of Recurrence Score (ROR) (nanoString, Seattle, WA, USA), EndoPredict ${ }^{\circledR}$ (EP) (Myriad Genetics, Salt Lake City, UT, USA), and Breast Cancer Index ${ }^{\text {SM }}$ (BCI).

With a clear majority of 58.3-92.9\%, the St. Gallen panelists see in the multigene assays (RS, ROR, EP) a possibility of gaining prognostically relevant information in patients with ER-positive and HER2-negative early breast cancer. However, most panelists do not believe that these assays provide any prognostically relevant information beyond 5 years. Here, the majority vote (63.2\%) was only positive for the ROR score whereas $40 \%$ of the panelists voted for the EP score. 
Table 1. Gene expression tests in luminal breast cancer: St. Gallen Consensus 2015

\begin{tabular}{llll}
\hline Test name & \multicolumn{2}{l}{ Support, $\%$} & \\
\cline { 2 - 4 } & $\begin{array}{llll}<5 \text {-Year } \\
\text { prognosis }\end{array}$ & $\begin{array}{l}>5 \text {-Year } \\
\text { prognosis }\end{array}$ & $\begin{array}{l}\text { Chemotherapy } \\
\text { indication }\end{array}$ \\
\hline PAM50 ROR (Prosigna) & $92 \%^{\mathrm{a}}$ & $63 \%^{\mathrm{a}}$ & $38 \%^{\mathrm{c}}$ \\
Recurrence Score (Oncotype Dx) & $83 \%^{\mathrm{a}}$ & $44 \%^{\mathrm{c}}$ & $80 \%^{\mathrm{a}, \mathrm{b}}$ \\
Endopredict & $70 \%^{\mathrm{a}}$ & $38 \%^{\mathrm{c}}$ & $38 \%$ \\
MammaPrint & $81 \%^{\mathrm{a}}$ & $33 \%^{\mathrm{c}}$ & $30 \%^{\mathrm{c}}$ \\
\hline
\end{tabular}

Consent with the following limitations:

aShould only be used in selected patients if all other criteria do not permit any clinical decision-making option.

${ }^{\text {b}}$ Validated clinical data are available for this assay only.

${ }^{c}$ The contemplated option differs in part from the evidence situation (see AGO).

PAM50 = Prediction analysis of Microarrays 50; ROR $=$ risk of recurrence.
Comment of the German group of experts: The German experts point out that the EP and the ROR provide equally valid data to assess the risk of recurrence in HR-positive postmenopausal patients even beyond the 5 th year following the initial diagnosis.

Reliable predictive significance regarding additional adjuvant chemotherapy is confirmed only for the Oncotype DX by the majority $(80.5 \%)$ of the St. Gallen panelists. So far, there are no prospective study data for any of the multigene assays which would prove their predictive significance; there are only retrospective data for Oncotype DX [2]. In general, the panelists recommend a multigene assay in addition to the Ki-67 in node-negative carcinomas (HR-positive, HER2-negative) if there is no consensus as to whether chemotherapy is indicated.

Comment of the German group of experts: Multigene tests are only justified if the indication for chemotherapy is not clear based on the histopathological findings. The statement of the German working group on the clinical benefit of the above-referenced multigene assays is summarized in table 1 . The evidence situation assessed by the AGO differs in part from that of the St. Gallen panel [2].

\section{Endocrine Treatment}

\section{Additional Ovarian Function Suppression for Premenopausal Patients?}

In light of the SOFT study [13], the St. Gallen panelists believe additional ovarian function suppression (OFS; with gonadotropinreleasing hormone $(\mathrm{GnRH})$, bilateral oophorectomy, or bilateral radiation of the ovaries) is an option for young ( $\leq 35$ years) premenopausal patients if they present with premenopausal estrogen serum levels after (neo)adjuvant chemotherapy.

Vote of the German group of experts: Consent. The German experts point out that aromatase inhibitors (AI) or tamoxifen combined with OFS have significantly more side effects than tamoxifen alone. This requires informing the patient diligently.

In addition, the St. Gallen panelists do believe OFS is indicated if: i) 4 or more lymph nodes are involved (89.7\%); ii) in G3 breast cancer (55.9\%); and iii) if a multigene test points toward an increased risk (60\%).
Vote of the German group of experts: No consent. Grading, lymph node involvement, and the results of a multigene test are not sufficient as sole factors to justify additional OFS. There are no prospective data to support this recommendation. In this situation, the German working group primarily sees an indication for chemotherapy.

\section{Tamoxifen or AIs plus OFS for Premenopausal Patients?}

The majority of the St. Gallen panelists voted for a combination with an $\mathrm{AI}$ in younger women ( $\leq 35$ years: $59.4 \%$ ) if 4 or more lymph nodes are involved (92.5\%), if there is an increased risk according to multigene tests $(65.8 \%)$, and - with a narrow majority (57.1\%) - in the case of a G3 carcinoma. A slight majority (51.2\%) were against AIs as combination partner in patients who remain premenopausal after completed adjuvant chemotherapy.

Vote of the German expert group: No consent. The questions selected for voting refer to a retrospective assessment of the SOFT study [13]. The SOFT study does not provide data on overall survival. Although the patient cohorts are comparable to only a limited extent, the data of the SOFT/TEXT study contradict the Austrian ABCSG12 study [14]. After a median follow-up of 9.4 years, there was no difference in disease-free survival (DFS) between tamoxifen alone versus anastrozole alone, but there was a decidedly higher risk of death for patients treated with anastrozole and OFS compared to tamoxifen/OFS (hazard ratio 1.63; 95\% confidence interval 1.05-1.45; $\mathrm{p}=0.030$ ).

The St. Gallen panelists voted with $56.7 \%$ for OFS over 5 years.

Comment of the German group of experts: The German experts recommend primarily 2-3 years, and - depending on side effects and risks - a maximum OFS period of 5 years. Before menopause, an AI must always be combined with OFS.

\section{The Postmenopausal Patient}

Treatment with tamoxifen remains an adequate option for postmenopausal patients with early hormone-sensitive breast cancer. However, preference should be given to an AI if the risk is increased. If an AI is indicated, it should be given 'upfront' if the risk is increased. In the case it is not well tolerated, the 'switch' to tamoxifen is an option after 2 years. 
Vote of the German group of experts: Consent. However, the German experts recommend AIs to be used for lobular carcinoma. They refer to the ATAC and BIG 1-98 data $[15,16]$.

\section{Therapy Duration up to 10 Years?}

Extended adjuvant aromatase inhibitor therapy (EAT) over the course of 10 years after surgery is an important option in patients at increased risk regardless of menopausal status. Before menopause, EAT can be done with tamoxifen, during the postmenopausal period with tamoxifen or an AI.

Vote of the German group of experts: Consent.

\section{Extended Endocrine Therapy after the 'Switch' Therapy}

If EAT is indicated in patients who received 2 years of treatment with tamoxifen followed by 3 years of treatment with an AI, these patients should either be treated for an additional 5 years with tamoxifen or for an additional 2 years with an AI according to the St. Gallen vote.

Vote of the German group of experts: Consent. The German group of experts consider that continued use of both an AI for 2 years or tamoxifen for 5 years might be clinically reasonable even if no clear data on a face-to-face comparison of this option are available to support this issue. In contrast, at present there are no data available to support the use of an AI beyond 5 years, as recommended by Burstein et al. [17]. There may be clinical scenarios where such a decision might be useful, but only on an individual informed consent basis.

\section{Extended Endocrine Treatment Following Upfront AI Therapy}

For this situation also there are currently no data from clinical trials. With a slight majority, the panelists rejected continued treatment with both tamoxifen and an AI. With 54.5\%, a narrow majority voted for not continuing any further endocrine therapy in these patients.

Vote of the German group of experts: Consent. The experts agree that in the case of unacceptable toxicity caused by an AI, tamoxifen can be used again. Tamoxifen exposure should be limited to 5 years in this setting. If treatment-related toxicities might influence compliance or adherence, a change to another endocrine treatment option is highly recommended to avoid treatment discontinuation in the adjuvant setting.

\section{Focus on Adjuvant Chemotherapy}

\section{Luminal A Breast Cancers}

Luminal A breast cancer is defined by high HR expression, HER2 negativity, and a low proliferation rate. Therefore, the therapy of choice is endocrine intervention. Additional adjuvant chemotherapy is generally not indicated and should only be considered on an individual basis if the risk is increased (e.g. $\geq 4$ involved lymph nodes, T3). If only 1-3 lymph nodes are involved and there are no additional risks, additional adjuvant chemotherapy is not indicated.
Vote of the German group of experts: Consent.

The majority (67.6\%) of the St. Gallen panelists regard lymphovascular tumor invasion as a sole indication for adjuvant chemotherapy.

Vote of the German group of experts: No consent.

\section{Luminal B Breast Cancer without Overexpression of HER2}

Endocrine treatment is an important component of systemic therapy also for patients with luminal B carcinoma. If the risk of recurrence is increased, adjuvant chemotherapy is indicated. If chemotherapy is indicated, an anthracycline/taxane-containing regimen is preferable.

Vote of the German group of experts: Consent. For example, the German experts recommend 4 cycles of anthracycline/cyclophosphamide followed by 12 weeks of paclitaxel administered weekly, or 6 cycles of docetaxel/doxorubicin/cyclophosphamide (TAC) administered every 3 weeks. If the risk of recurrence is high (e.g. $\geq 4$ involved lymph nodes), a dose-dense regimen with granulocytecolony stimulating factor (G-CSF) support is one therapy option.

In the case of low risk scores in the available multigene expression tests (RS, MP, PAM50 ROR, EP), there is no indication for adjuvant chemotherapy in patients with up to 3 involved lymph nodes.

Vote of the German group of experts: Consent. The first prospective data of the PlanB study (HR-positive, HER2-negative) show that patients with $0-3$ involved lymph nodes and a low risk score $(\leq 11)$ have an excellent 3-year survival rate of over $98 \%$ [18]. In this context, the results of the ongoing clinical trials (TailorX, RxPONDER, MINDACT, PlanB, ADAPT) need to be awaited.

\section{TNBC}

For patients with TNBC (ER, PR, HER2), anthracycline/taxanecontaining regimens are the therapy of choice. The same applies to patients with a BRCA mutation. Dose-dense regimens (with G-CSF support) can be an option according to the panelists (yes $45 \%$, no $52.5 \%)$. The majority (92.9\%) of panelists do not see a general indication for platinum-containing regiments in early TNBC.

Vote of the German group of experts: Consent.

A slight majority (57.9\%) of the St. Gallen panelists consider platinum in patients with TNBC and a BRCA mutation as an additional option.

Comment of the German group of experts: The German experts recommend a more differentiated approach. Because of the lack of prospective data, they do not agree to the use of platinum in the adjuvant situation. These patients should receive neoadjuvant treatment, and, if possible, they should be included in clinical trials.

\section{HER2-Positive Early Breast Cancer}

If HER2 positivity is proven according to the requirements of the ASCO/CAP guidelines [19], an adjuvant anti-HER2 targeted therapy is indicated even at tumor stage T1b, according to the majority vote of the St. Gallen panelists (81.4\%). From stage T1c and 
Table 2. Superiority of carboplatin-containing regimens in the neoadjuvant setting [1]

\begin{tabular}{|c|c|c|c|}
\hline Author [ref.] & Study & Regimen & $\mathrm{pCR}$ rate \\
\hline $\begin{array}{l}\text { Sikov WM et al. } \\
\text { [22] }\end{array}$ & $\begin{array}{l}\text { CALGB } 40603 \\
\text { phase II }\end{array}$ & $\begin{array}{l}\text { paclitaxel } 80 \mathrm{mg} / \mathrm{m}^{2} \mathrm{qw} \times 12+\mathrm{Cb} \\
\text { AUC } 6 \mathrm{q} 3 \mathrm{w} \times 4-\mathrm{dd} \text { AC } \mathrm{q} 2 \mathrm{w} \times 4\end{array}$ & $\begin{array}{l}\text { TNBC } \pm \text { Cb: } 54 \text { vs. } 41 \% \\
\text { (ypT0/is ypN0) }\end{array}$ \\
\hline $\begin{array}{l}\text { Von Minckwitz G } \\
\text { et al. [23] }\end{array}$ & $\begin{array}{l}\text { GeparSixto } \\
\text { phase II }\end{array}$ & $\begin{array}{l}\text { NPLD } 20 \mathrm{mg} / \mathrm{m}^{2} \mathrm{qw} \times 18+\text { paclitaxel } \\
80 \mathrm{mg} / \mathrm{m}^{2} \mathrm{qw} \times 18+\mathrm{Cb} \text { AUC } 1.5 \mathrm{qw} \\
\times 18+\mathrm{Bev} 15 \mathrm{mg} / \mathrm{kg} \mathrm{q} 3 \mathrm{w} \times 6\end{array}$ & $\begin{array}{l}\text { TNBC } \pm \text { Cb: } 53 \text { vs. } 37 \% \\
\text { (ypT0 ypN0) }\end{array}$ \\
\hline Ando M et al. [24] & phase II & $\begin{array}{l}\text { paclitaxel } 80 \mathrm{mg} / \mathrm{m}^{2} \mathrm{qw} \times 12+\mathrm{Cb} \\
\text { AUC } 5 \mathrm{q} 3 \mathrm{w} \times 4-\mathrm{FEC} \mathrm{q} 3 \mathrm{w} \times 4\end{array}$ & $\mathrm{TNBC} \pm \mathrm{Cb}: 61$ vs. $26 \%$ \\
\hline
\end{tabular}

$\mathrm{pCR}=$ Pathologic complete remission; $\mathrm{AUC}=$ area under the curve; $\mathrm{dd}=$ dose-dense; $\mathrm{AC}=$ adriamycin, cyclophosphamide; NPLD = non-pegylated doxorubicin; TNBC = triple-negative breast cancer; $\mathrm{Cb}=\mathrm{carboplatin}$; $\mathrm{Bev}=$ bevacizumab; qw = weekly; q2 $\mathrm{w}=$ every 2 weeks; $\mathrm{q} 3 \mathrm{w}=$ every 3 weeks; FEC = 5-fluorouracil, epirubicin, cyclophosphamide; CALGB = Cancer and Leukemia Group B.

higher, all St. Gallen panelists voted for adjuvant chemotherapy in combination with an anti-HER2 targeted therapy.

Vote of the German group of experts: Consent. Adjuvant chemotherapy should preferably consist of a sequential anthracycline/ taxane-containing regimen. The anti-HER2 targeted therapy is applied in parallel to the taxane. Standard is a 1-year therapy with trastuzumab. In patients with node-negative $\mathrm{T} 1 \mathrm{~b} / \mathrm{c}$ carcinoma, it may make sense to combine $12 \times$ paclitaxel (weekly) with trastuzumab (1 year; without anthracyclines) [20].

\section{Focus on Neoadjuvant Therapy}

\section{HER2-Positive Breast Cancer}

The standard for neoadjuvant therapy of HER2-positive breast cancer is sequential anthracycline/taxane-based chemotherapy plus trastuzumab. In addition, the majority (73\%) of the St. Gallen panelists also see a neoadjuvant indication for dual horizontal blockade with pertuzumab in combination with trastuzumab and a taxane.

Vote of the German group of experts: No consent with regard to the dual horizontal blockade. In Europe, pertuzumab/trastuzumab/ taxane - in contrast to the United States - is currently not approved for neoadjuvant treatment of HER2-positive breast cancer. Without approval, the dual blockade with pertuzumab and trastuzumab in the neoadjuvant situations can presently only be decided upon on an individual basis in Germany. The German experts add that for patients with cardiac risks, the anthracycline-free $\mathrm{TCH}$ regimen (docetaxel, carboplatin, trastuzumab) is an additional neoadjuvant therapy option.

\section{TNBC}

Sequential regimens with an anthracycline combination followed by a taxane are indicated in TNBC. The inverse sequence achieves at least comparable response rates.

Vote of the German group of experts: Consent. The results of the GeparSepto study demonstrated a significantly higher pathologic complete remission (pCR) rate with weekly nab-paclitaxel compared to weekly paclitaxel - each followed by 4 cycles of epirubicin/ cyclophosphamide (EC) administered every 3 weeks. The benefit was shown for all patients and was particularly pronounced in TBNC (doubling of the pCR rate) [21]. Further study results (ETNA, ADAPT) are expected.

The St. Gallen panel does not recommend platinum for neoadjuvant treatment of TNBC.

Vote of the German group of experts: No consent. Data from several prospective, randomized, neoadjuvant studies [22-24] demonstrate a clear advantage of platinum, particularly in patients with a family history or BRCA mutations (table 2). For this reason, the AGO has assigned a ' + ' recommendation for neoadjuvant platinum [1].

\section{Luminal A Breast Cancer}

The majority of the St. Gallen panelists believe that neoadjuvant chemotherapy is an option for patients who cannot undergo BCS.

Vote of the German group of experts: No consent. Currently, neoadjuvant chemotherapy is not an option in luminal A breast cancers. The German experts emphasize that neoadjuvant chemotherapy is rarely indicated in patients with luminal A breast cancer. Based on the low sensitivity to chemotherapy, it seems unlikely that the tumor would decrease in size (pCR) and outcome subsequently improve.

\section{Neoadjuvant Endocrine Therapy}

Neoadjuvant endocrine therapy can be a meaningful option for postmenopausal patients with an endocrine sensitive breast cancer.

Vote of the German group of experts: Limited consent. Based on the limited available data, neoadjuvant endocrine therapy should only be considered for older patients with clinically relevant internal comorbidities.

Optimum therapy duration is not known. The majority of the St. Gallen panelists recommend administering a neoadjuvant endocrine therapy for either several (4-8) months or up to the maximum response.

Comment of the German expert group: The German experts point out that these patients should undergo surgery if at all possible. 


\section{Adjuvant Use of 'Bone-Modifying Agents' (Bisphosphonates, Denosumab)}

\section{The Postmenopausal Patient}

The adjuvant use of a bisphosphonate (BP; zoledronic acid every 6 months, or orally with clodronic acid daily) in addition to adjuvant endocrine therapy can be an option for postmenopausal patients with the goal to prolong DFS.

Vote of the German group of experts: Consent. The data of a large meta-analysis show that an adjuvant effect of BP is limited to postmenopausal patients [25]. It should be pointed out that BP are only approved for the treatment of osteoporosis and osseous metastases.

\section{The Premenopausal Patient}

Based on the data of the Austrian ABCSG 12 study [13], adjuvant BP administration in premenopausal patients along with $\mathrm{GnRH}$ may be an option in certain cases; however, it is not the general standard. There are no data and therefore no indication for adjuvant use of denosumab.

Vote of the German group of experts: Consent.

\section{Focus on Elderly and Younger Patients}

In patients without clinically relevant (significant) comorbidities, the use of adjuvant standard (chemo)therapy should not generally be made dependent on age. The same applies to the question of whether after BCS a postmenopausal patient with ER-positive breast cancer should not have adjuvant radiation if adjuvant endocrine therapy is continued. The indication for an adjuvant therapy should be based on life expectancy (biological age).

Vote of the German group of experts: Consent.

\section{Testing for Mutations}

In younger patients ( $<40$ years) with TNBC, genetic counselling along with BRCA1/2 testing should be carried out according to the majority vote $(73 \%)$ of the St. Gallen panel. On the additional question of whether this should also apply to the age limit of $<60$ years, the St. Gallen panel voted 50:50. The majority (90.9\%) voted in favor of the test for patients with TNBC and a positive family history. The St. Gallen panel rejected with a narrow majority (50\%) further mutation tests in other genes.

Vote of the German group of experts: Consent.

A test for high-risk mutations (such as PALB2) does not generally make sense for all breast cancer patients; however, it is recommended if the family history is positive and if the patient is $\leq 35$ years. There is no general indication for testing patients $<50$ years; however, testing is indicated in those with ER-negative and HER2negative breast cancer (70\%).

Vote of the German group of experts: Consent. However, the test should only be performed if therapeutically relevant. The German experts recommend patients with ER- and HER2-negative breast cancers should be generally tested regardless of the patient's age, provided the result can affect the therapy decision (e.g. prophylactic mastectomy, bilateral prophylactic salpingoophorectomy).
The probability to find any mutations decreases with increasing age.

Vote of the German group of experts: Consent plus supplement: This applies also to patients with 'basal-like' breast cancer.

The presence of a BRCA1/2 mutation can only affect the neoadjuvant therapy; however, it does not affect the adjuvant therapy decision due to lack of data.

Vote of the German group of experts: Consent.

\section{Fertility Preservation in Young Patients}

Young patients should be informed and counseled on the possibility of fertility preservation if indicated. The use of a GnRH analogue before and during adjuvant chemotherapy may be an option in individual cases.

Vote of the German group of experts: Consent.

The majority $(78.9 \%)$ of the St. Gallen panelists voted for offering young patients $(<40$ years) with HR-negative breast cancer OFS in addition to the chemotherapy.

Vote of the German group of experts: No consent. With reference to the current therapy recommendations of AGO Mamma, the German experts recommend OFS based on individual criteria [2].

\section{Breast Cancer and Pregnancy}

If a patient is diagnosed with breast cancer during pregnancy, then labor should not be induced prematurely. It is possible to undergo BCS. It is possible to perform lymph scintigraphy and SNB. If endocrine therapy is indicated, it should be started post-partum.

Vote of the German group of experts: Consent.

With a low majority (52.6\%), the panelists recommend that it makes sense to reconstruct the breast immediately in patients who undergo mastectomy during pregnancy.

Vote of the German expert group: No consent. Experts refer to a longer duration of surgery and an increased risk of complications if immediate reconstruction is performed.

If a patient with breast cancer wants to become pregnant, the ongoing treatment can be interrupted. The majority (60.6\%) of the St. Gallen panelists believe that endocrine therapy should only be interrupted after 18-30 months provided a pregnancy is desired. The majority (61.1\%) recommends considering this only if there is no notably increased risk of recurrence.

Vote of the German group of experts: Consent. The German experts emphasize that the patient should have received tamoxifen for at least 18 months because thereafter the annual gain through adjuvant therapy decreases in accordance with the EBCTCG analysis.

\section{Diet and Physical Activity}

Patients with breast cancer do not require any special diet. However, balanced nutrition is generally important for overall wellbeing and health. A positive effect on the breast cancer-specific 
survival rate is not proven. The same applies to regular physical activity and moderate exercise, as well as avoiding significant overweight. Supplementation is recommended in the case of vitamin D deficiency.

Vote of the German group of experts: Consent.

\section{Acknowledgement}

The post-St. Gallen meeting was organized and executed by I-MED-Institute $\mathrm{GmbH}$. Celgene $\mathrm{GmbH}$ provided a grant without restrictions on the content. The authors are solely responsible for the preparation of the manuscript. The authors would like to thank Prof. Diethelm Wallwiener of Tübingen for checking through the manuscript and Birgit-Kristin Pohlmann of Nordkirchen for her editorial support.

\section{Disclosure Statement}

Michael Untch has no conflict of interest. Nadia Harbeck received honoraria from Celgene, Genomic Health, NanoString, Novartis, Roche. Jens Huober received honoraria from Novartis, Celgene, Roche, GSK, Genomic Health, and a research grant from GSK. Gunter von Minckwitz has no conflict of interest. Bernd Gerber has no conflict of interest. Hans-Heinrich Kreipe received honoraria from Roche, Genomic Health, AstraZeneca, Novartis. Cornelia Liedtke received honoraria from Genomic Health, Roche, Celgene, and a research grant from Eisai. Norbert Marschner has no conflict of interest. Volker Möbus received honoraria from Amgen, Celgene, Roche, and a research grant from Amgen. Heike Scheithauer received honoraria from Makosch media, Amgen, Celgene, NanoString. Andreas Schneeweiss received honoraria from Roche, Celgene, Amgen, and a research grant from Roche. Christoph Thomssen received honoraria from Amgen, AstraZeneca, Celgene, Genomic Health, NanoString, Novartis, Pfizer, Roche, Teva. Christian Jackisch received honoraria and a travel grant from Celgene. Matthias W. Beckmann has no conflict of interest. Jens-Uwe Blohmer received honoraria from Roche, Novartis, Pfizer, Celgene, TEVA, Amgen, and a research grant from DIZG. Serban-Dan Costa has no conflict of interest. Thomas Decker has no conflict of interest. Ingo Diel has no conflict of interest. Peter A. Fasching received honoraria from Amgen, Novartis, Roche, Pfizer, TEVA, Genomic Health, GSK, NanoString, and a research grant from Novartis, Amgen. Tanja Fehm has no conflict of interest. Wolfgang Janni received honoraria from Roche, Novartis, Sanofi-Aventis, AstraZeneca, Pfizer, Chugai, Amgen, and research grants from Roche, Novartis, Sanof-Aventis, AstraZeneca, Pfizer, Chugai, Amgen. Hans-Joachim Lück received honoraria from Roche, Novartis, Eisai, Celgene. Nicolai Maass has no conflict of interest. Anton Scharl received honoraria from Celgene, Roche, Novartis, Teva, Amgen, AstraZeneca, Sanofi, Glaxo, Eisai, Riemser, JanssenCilag. Sibylle Loibl received research grants from Celgene, Amgen, Roche, Novartis, Pfizer, Abbott.

\section{References}

$\nabla_{1}$ Coates AS, Winer EP, Goldhirsch A, et al.: Tailoring therapies - improving the management of early breast cancer: St Gallen International Expert Consensus on the Primary Therapy of Early Breast Cancer 2015. Ann Oncol 2015; Epub ahead of print.

2 www.ago-online.de (version v1, updated 08.04.2015).

$\checkmark 3$ Boughey JC, Suman VJ, Mittendorf EA, et al.: Sentinel lymph node surgery after neoadjuvant chemotherapy in patients with node positive breast cancer: the ACOSOG Z1071 (Alliance) clinical trial. JAMA 2013;310: 1455-1461.

4 Kühn T, Bauerfeind I, Fehm T, et al.: Sentinel-lymphnode biopsy with breast cancer before and after neoadjuvant chemotherapy (SENTINA): a prospective multi-center cohort study. Lancet Oncol 2013;14:609618.

5 Boughey JC, Ballman KV, Symmans WF, et al.: Methods impacting the false negative rate of sentinel lymph node surgery in patients presenting with node positive breast cancer (T0-T4,N1-2) who receive neoadjuvant chemotherapy - results from a prospective trial ACOSOG Z1071 (Alliance). SABCS 2014;P2-01-02.

6 Giuliano AE, McCall L, Beitsch P, et al.: Locoregional recurrence after sentinel lymph node dissection with or without axillary dissection in patients with sentinel node metastases: the American College of Surgeons Oncology Group Z0011 randomized trial. Ann Surg 2010;252:426-432.

7 www.astro.org (Guidelines updated 19.03.2015).

8 www.estro.org (2012).

9 Smith BD, Arthur DW, Buchholz TA, et al.: Consensus Statement der ASTRO, IJROBP 2009;74:987-1001.

10 Polgàr C, Van Limbergen E, Pötter R, et al.: Patient selection for accelerated partial-breast irradiation (APBI) after breast-conserving surgery: recommendations of the Groupe Européen de Curiethérapie-European Society for Therapeutic Radiology and Oncology (GECESTRO) breast cancer working group based on clinical evidence (2009). Radiother Oncol 2010;94:264-273.
11 Poortmans P, Struikmans H, Kirkove C, et al.: Irradiation of the internal mammary and medical supraclavicular lymph nodes in stage I to III breast cancer: 10 years results of the EORTC Radiation Oncology and Breast Cancer Groups phase III trial 22922/10925. ECCO 2013, Amsterdam, Presidential Session, LBA 2.

12 Denkert C, von Minckwitz G, Brase JC, et al.: Tumorinfiltrating lymphocytes and response to neoadjuvant chemotherapy with or without carboplatin in human epidermal growth factor receptor 2-positive and triplenegative primary breast cancers. J Clin Oncol 2015;33: 983-991.

13 Francis PA, Regan MM, Fleming GF, et al.: Adjuvant ovarian suppression in premenopausal breast cancer. N Engl J Med 2015;372:436-446.

14 Gnant M, Mlineritsch B, Stoeger H, et al.: Zoledronic acid combined with adjuvant endocrine therapy of tamoxifen versus anastrozol plus ovarian function suppression in premenopausal early breast cancer: final analysis of the Austrian Breast and Colorectal Cancer Study Group Trial 12. Ann Oncol 2015;26:313-320.

15 Cuzick J, Sestak J, Baum M, et al.: Effect of anastrozole and tamoxifen as adjuvant treatment for early-stage breast cancer: 10 year analysis of the ATAC trial. Lancet Oncol 2010;11:1135-1141.

16 Regan MM, Neven P, Giobbie-Hurder A, et al.: Assessment of letrozole and tamoxifen alone and in sequence for postmenopausal women with steroid hormone receptor-positive breast cancer: the BIG 1-98 randomized clinical trial at 8,1 years median follow-up. Lancet Oncol 2011;12:1101-1108.

17 Burstein HJ, Temin S, Anderson H, et al.: Adjuvant endocrine therapy for women with hormone receptorpositive breast cancer: American Society of Clinical Oncology clinical practice guideline focused update. J Clin Oncol 2014;32:2255-2269.

18 Nitz U, Gluz O, Kates RE, et al.: Prognostic impact of discordance between different risk assessment tools in early breast cancer: early outcome analysis from the prospective phase III WSG-PlanB trial. SABCS 2014; P4-11-01.
19 Wolff AC, Hammond MEH, Hicks DG, et al.: Recommendations for human epidermal growth factor receptor 2 testing in breast cancer: American Society of Clinical Oncology/College of American Pathologists clinical practice guidelines update. J Clin Oncol 2013; 31:3997-4013.

20 Tolaney SM, Barry WT, Dank CT, et al.: Adjuvant paclitaxel and trastuzumab for node-negative, Her2-positive breast cancer. New Engl J Med 2015;372:134-141.

21 Untch M, Jackisch C, Schneeweiss A, et al.: A randomized phase III trial comparing neoadjuvant chemotherapy with weekly nanoparticle-based paclitaxel with solvent based paclitaxel followed by anthracycline/cyclophosphamide for patients with early breast cancer (GeparSepto); GBG 69. SABCS 2014;S2-07.

22 Sikov WM, Berry DA, Perou CM, et al.: Impact of the addition of carboplatin and/or bevacizumab to neoadjuvant once-per-week paclitaxel followed by dosedense doxorubicin and cyclophosphamide on pathologic complete response rates in stage II to III triplenegative breast cancer: CALGB 40603 (Alliance). J Clin Oncol 2015;33:13-21.

23 Von Minckwitz G, Schneeweiss A, Loibl S, et al.: Neoadjuvant carboplatin in patients with triple-negative and HER2-positive early breast cancer (GeparSixto; GBG 66): a randomised phase 2 trial. Lancet Oncol 2014;15:747-756.

24 Ando M: Randomized phase II study of weekly paclitaxel with and without carboplatin followed by cyclophosphamide/epirubicin/5-fluorouracil as neoadjuvant chemotherapy for stage II/IIIA breast cancer without HER2 overexpression. Breast Cancer Res Treat 2014;145:401-409.

25 Coleman R, Gnant M, Paterson A, et al.: Effects of bisphosphonate treatment on recurrence and cause-specific mortality in women with early breast cancer. A meta-analysis of individual patient data from randomized trials. SABCS 2013;S4-07. 